\title{
Sexual violence against female sex workers in The Gambia: a cross-sectional examination of the associations between victimization and reproductive, sexual and mental health
}

\author{
Jennifer A Sherwood ${ }^{1 *}$, Ashley Grosso ${ }^{1}$, Michele R Decker $^{1}$, Sarah Peitzmeier ${ }^{1}$, Erin Papworth ${ }^{1}$, Daouda Diouf², \\ Fatou Maria Drame ${ }^{3}$, Nuha Ceesay ${ }^{4}$ and Stefan Baral ${ }^{1}$
}

\begin{abstract}
Background: Female sex workers (FSW) are a vulnerable population for sexual violence and poor sexual and reproductive health outcomes. Sexual violence against FSW has not been widely studied in The Gambia. This study will report the prevalence of and evaluate the health issues correlated with forced sex perpetrated by clients against FSW in The Gambia, and will secondly aim to inform future research and efforts to improve health outcomes for survivors of violence.
\end{abstract}

Methods: A cross-sectional survey was administered among 251 FSW accrued through a combination of chain referral and venue-based sampling in The Gambia. Eligibility criteria included being over 16 years old and having exchanged sex for money, goods, or favors in the past 12 months.

Results: There is a high prevalence of sexual violence against FSW in The Gambia, with 29\% ( $n=70$ ) of participants reporting a client forced them to have sex in their lifetime. Women who reported forced sex by a client were more likely to report symptoms of depression (aOR 2.15, Cl: $1.10-4.16$ p < 0.05), unwanted pregnancy (aOR: 2.69, Cl: 1.12 $6.49 \mathrm{p}<0.05)$ and report "no", "difficult" or "somewhat difficult" access to condoms (aOR: 3.31, Cl: $1.76-6.26 \mathrm{p}<.01$ ) compared to women who did not report forced sex. Client-perpetrated forced sex was also negatively associated with receiving any sexually transmitted infection (STI) test in the past 12 months (aOR: 0.49, Cl: .26 - .91 p<.05).

Conclusion: FSW who experience sexual violence by a client are more likely to experience poor sexual, reproductive and mental health outcomes. Responding to sexual violence among FSW, including providing survivors with access to post-exposure prophylaxis, emergency contraception, and mental health services, must be a priority given the prevalence of forced sex and links with poor health outcomes. Efforts to reduce sexual violence against FSW is a vital strategy to improve the health and safety of FSW as well as impact the spread of HIV/STIs in The Gambia.

Keywords: Female sex workers, The Gambia, Forced sex, Violence, HIV/STIs, Reproductive health

\footnotetext{
* Correspondence: jenifersherwood@gmail.com

'Johns Hopkins School of Public Health, 615 N Wolfe St. \#5041, Baltimore, MD 21205, USA

Full list of author information is available at the end of the article
} 


\section{Background}

Female sex workers (FSW) are among the most vulnerable populations for the acquisition and transmission of both HIV and STIs. In many parts of sub-Saharan Africa such as Guinea, Benin, and Senegal the national HIV prevalence is reported as $1.7 \%$ (2010), 1.5\% (2007) and $1.0 \%$ (2010) compared to $36.7 \%, 40.9 \%$, and $19.9 \%$ among FSW (OR 33.1, 44.2 and 23.7 respectively) [1-6]. In The Gambia, the most recent HIV prevalence data report a prevalence of $15.9 \%$ (2011) [7] and 35.1\% (1993) [8] among FSW, compared to $1.7 \%$ in the general population [9]. Among the factors that increase FSWs' risk of HIV is the high rate of sexual violence that threatens women's ability to negotiate condoms [10-13] or engage in HIV risk-reduction behaviors $[11,13,14]$. The estimated prevalence of sexual violence victimization among FSW ranges from 33\%-72\% globally [15-17]. Data specifically from African contexts, for instance, Kenya (43\%) [18], Namibia (72\%) [17], and Rwanda (37\%), [19] also report a high prevalence of victimization.

Sexual violence victimization is a likely barrier to effective STI/HIV prevention among FSW [20] and women in the general population [21]. Multiple studies have demonstrated that sexual violence against FSW has been associated with decreased condom use [11,12,22,23], condom failure [24], HIV prevalence [13,25], and other STI symptoms [24]. Women are put at direct risk of HIV/STIs during forced sex due to condom non-use and the increased likelihood for perpetrators of forced sex to be HIVinfected [20,26-29]. Forced sex can also increase indirect risk for HIV by influencing future patterns of sexual risk taking including decreased condom use and increased substance use during sex $[20,26]$. Finally, forced sex has been associated with increased stigma and social vulnerability as well as decreased care-seeking for health issues, which may influence future HIV and STI care [30]. Female sex workers are subject to abuse by many types of perpetrators including police, pimps, partners and clients. While some reports do not specify type of perpetrator in data collection, where assessed, clients are often the predominant perpetrator of sexual violence $[13,23,31]$.

FSW have been shown to be at high risk for poor reproductive health outcomes including unintended pregnancy. Research examining the contraceptive needs of FSW in Madagascar reported that $52 \%$ of participants had an unintended pregnancy and $45 \%$ reported having an induced abortion [32]. Similar results were found among FSW in Kenya where 52\% reported an unintended pregnancy over their lifetime and 32\% reported an induced abortion [33]. While induced abortion is not in itself a poor health outcome, it is a valuable marker of unintended pregnancy. In settings where access to abortion is illegal or restricted, abortions more commonly take place in unsafe environments that can lead to serious negative health consequences [34,35]. Among the factors contributing to these poor reproductive health outcomes is the high prevalence of sexual violence among FSW, which has been associated with non-condom use $[22,23]$ and has been given as a common reason for seeking an abortion [36,37].

Forced sex has also been found to be associated with depression among FSW, although the link has not been widely studied. The association between intimate partner violence (IPV) and depression has been more extensively explored. A range of poor mental health outcomes are associated with IPV in diverse samples of women not limited to FSW, including depression, anxiety, and posttraumatic stress disorder [38-41]. There have been few FSW-specific studies examining mental health outcomes associated with forced sex, but these include a study among $624 \mathrm{FSW}$ in Mexico, where $86 \%$ of participants screened positive for depression, and victims of forced sex during sex work were significantly more likely to screen positive than those who had not experienced forced sex (OR 2.65 CI: $1.39-3.90 \mathrm{p}<.001$ ) [25]. A Nepalese study among 210 FSW found similarly high reports of depression (82\%) among participants; however, victims of forced sex were not significantly more likely to suffer from depression than non-victims $(80 \%$ vs. $82 \%$ respectively) [42].

Health outcomes for FSW in The Gambia including STIs, unintended pregnancy, abortion and depression have not been widely studied. In The Gambia, sex work is officially illegal [43]. Therapeutic abortions are also illegal, except in situations where it is necessary to save a women's life [44]. Little is known about sexual violence victimization, or its associations with health outcomes, among Gambian women in the general population or among FSW. Bolstering the body of research on sexual violence in The Gambia could be useful in the production of national guidelines for a response to violence and in improving FSW and women's health more generally. The analyses presented here contribute to filling this gap by reporting the prevalence of violence victimization among FSW as well as examining the health outcomes associated with forced sex for these women.

\section{Methods}

\section{Participants/collection methods}

Inclusion criteria for participants included being born a woman, reporting having sold sex for money, goods, or favors in the past 12 months, being over the age of 16 , residing in The Gambia, and being able to provide verbal consent in English, Wolof or Mandinka. Participants were recruited for a cross-sectional survey between July and August of 2011 through a combination of peerbased, chain-referral, and convenience sampling at sex work venues. The initial participants were members of 
community-based organizations in The Gambia and varied in age, location of birth, education levels, and selfreported HIV status. Participants were then recruited based on peer referral as well as recruited by study staff from known sex work venues in the Greater Banjul Area and the smaller towns of Barra, Farafenni, Basse and Soma [7]. Diverse seed selection and recruitment in different regions of The Gambia were used to increase the representativeness of this non-probability sample. Sample size calculations were based on an estimated $20 \%$ HIV prevalence among FSW in Senegal, which requires a minimum of 175 participants to detect a significant difference (OR 2.0) between participants with differing HIV protective behaviors (such as consistent condom use).

Ultimately, recruitment generated a total of 251 participants who provided informed consent to participate in the study. The participants completed a face-to-face questionnaire administered by a trained female interviewer at a dedicated site in a private room where no identifying information was collected. Participants could refuse to answer any question. The interview lasted approximately 60 minutes, after which the participants were tested for HIV in accordance with the national guidelines using parallel rapid testing with Determine (Alere, Waltham, Massachusetts, USA) and Hexagon HIV (HUMAN Diagnostics Worldwide, Wiesbaden, Germany). All indeterminate tests, $10 \%$ of negative tests, and all positive tests were re-tested using enzyme-linked immunosorbent assays in the National Public Health Lab of The Gambia [7]. Study staff provided pre-test and optional post-test counseling, as well as referrals to government antiretroviral therapy (ART) clinics to those who tested HIVpositive. Participants who screened positive for other adverse health outcomes including symptoms of STIs or depressive symptoms were given referrals to local health clinics and available psychological services. Data from the questionnaires were dually entered by two data entrants. A Visual Basics module in Microsoft Access was used to compare the data and reconcile discrepancies.

\section{Ethics}

Data collection was approved by the National Scientific and Ethics Committee in The Gambia and secondary data analysis was approved by the institutional review board at Johns Hopkins School of Public Health. Per WHO ethical guidelines for violence research [45], referrals for counseling services for gender-based violence were provided through Action AID.

\section{Study measures}

All measures were self-reported, except for HIV status, which was tested for using Determine and Hexagon HIV rapid tests. The primary exposure, forced sex by a client, was defined as ever having a client use force or violence to make the participant have sex or certain kinds of sex. Participant's responses were dichotomous, (yes/no). The primary exposure for this analysis was specifically forced sex by a client as opposed to a range of sexual or physical violence variables. This exposure was chosen based on the more direct pathway between forced sex and sexual and reproductive health outcomes [46], which is the primary focus of this paper. Data on forced sex by nonclient perpetrators was not collected using consistent language in this survey, using the word "rape" as opposed to "forced sex", and was therefore not included as an exposure in this analysis. The primary exposure for this analysis is consistent with best practices when measuring sexual violence, which do not require that participants self-identify as being "raped" when measuring the prevalence of forced sex [47], as well as data showing that the primary perpetrators of sexual violence against FSW are clients [13,23,31].

Participants also self-reported demographic characteristics including age, marital status, number of children, education level (highest attained), city of origin, and the age at which they entered sex work. Age of entry was assessed by asking, "How old were you the first time you traded or sold sex or sexual acts in exchange for money, favors or goods?" The length of time that a woman has been in sex work was then calculated by subtracting the age she reported to have entered sex work from her current reported age. Participants also self-reported an additional set of violent, coercive, and otherwise potentially traumatic experiences including: if they, "had ever been beaten up as a result of selling sex", "had ever felt verbal or physical harassment as a result of selling sex", "had ever been tortured as a result of selling sex", "had ever been blackmailed as a result of selling sex", "have ever been offered more money to have non-condom protected sex" or "had ever been to jail or prison". Primary health outcomes assessed were: depressive symptoms, defined as reporting a sad or depressed mood for more than 2 weeks at a time in the past 3 years; receiving an STI test, defined as having been tested for syphilis, gonorrhea, chlamydia or herpes in the past 12 months; unwanted pregnancy, defined as ever having a pregnancy that was unwanted at the time when the woman found out she was pregnant; and condom availability, defined as responding "no access" or "difficult access" or "somewhat difficult access" to condoms as opposed to reporting "somewhat easy access" or "very easy access" when asked, "Do you have access to condoms when you need them?" The question assessing depressive symptoms was not a validated scale intended to provide a clinical diagnosis, but rather an initial screen signaling the potential need for further mental health evaluation. 


\section{Statistical analysis}

Prevalence estimates of client-perpetrated forced sex were calculated overall and by demographic characteristics. Based on the type and distribution of the variable, the chi-squared test and the Wilcoxon rank-sum test were selected to evaluate the difference between groups of participants exposed and unexposed to forced sex. Descriptive analysis and bivariate logistic regression models were constructed to explore associations of forced sex by a client with other forms of abuse, as well as the available mental and physical health outcomes. Models were then adjusted for participant age, age of entry into sex work, years in sex work, and HIV status. The multivariate model for unwanted pregnancy was additionally adjusted for number of children. Possible confounders were selected based on previous literature showing the associations between these variables and the health outcomes [48-57]. Models were adjusted for age and number of years in sex work in order to control for women that may be at higher risk for negative health outcomes because they are older or have been participating in sex work longer. Age of entry was controlled for because earlier age of entry has been shown to be associated with higher levels of reported abuse, reporting more drug and alcohol use, as well as childhood abuse and depression as an adult [48-50]. HIV status was controlled for because HIV positive status has shown to be associated with depression [51,52], unwanted pregnancy [53], and increased exposure to sexual violence [54-56]. Number of children was controlled for in this analysis based on norms in the field where previous studies examining unwanted pregnancy control for fertility history (including the number of previous children) $[56,57]$. Reports of "rape" by any perpetrator did not differ significantly by group exposed and unexposed to forced sex by a client and so was not controlled for in adjusted analysis. Missing data $(<4 \%)$ was dealt with through listwise deletion. Data were analyzed using Stata statistical software 12.0 [58].

\section{Results}

Lifetime client-perpetrated forced sex was prevalent at $29 \%(70 / 251)$. Participants were between the ages of $17-$ 51 at the time of interview, with a median age of 31 . Among participants in this sample, the median number of children was 1 , the median age of entry into sex work was 25 , and the median number of years spent in sex work at the time of the interview was 4 . The participants were most likely to be widowed/divorced, $69 \%$ (173/251), followed by being single or never married, 23\% (57/251). Over a third of participants, 37\% (92/251), completed some or all of secondary school, $30 \%(75 / 251)$ completed some or all of primary school, 30\% (74/251) had never attended school and $3 \%(6 / 251)$ had a post-high school education. The study found that $17 \%(40 / 251)$ of participants were living with HIV. Of those who had experienced forced sex, 19\% (13/40) were HIV positive compared to $15 \%(26 / 40)$ of women who had not experienced forced sex [Table 1]. There were no significant differences in socio-demographic characteristics between the groups who experienced forced sex by clients compared to those who had not.

Other forms of abuse against FSW were common [Table 2]. About 1 out of 5, 21\% (49/251), reported ever having been beaten up as a result of selling sex, and of these women the most common reported perpetrator was regular clients, $26 \%$ (13/49), followed by a one-time client, 20\% (10/49), non-paying partner, 20\% (10/49), uniformed police officer, $18 \%$ (9/49), and family member, $12 \%(6 / 49)$. Additionally, $40 \%(96 / 251)$ of the participants reported having been verbally or physically harassed as a result of selling sex, and 33\% (81/251) reported having been tortured. FSW also reported high levels of coercion, with $42 \%(102 / 251)$ of women indicating they had been offered more money to have sex without a condom, and $25 \%(60 / 251)$ reporting having been blackmailed. In adjusted analyses, women who experienced forced sex by a client were significantly more likely to have experienced physical abuse as a result of selling sex (31.9\% vs. $16.6 \%$ aOR: 2.44 , CI: $1.22-4.85$ $\mathrm{p}<.05)$, been tortured as a result of selling sex $(44.3 \%$ vs. $28.8 \%$ aOR: 1.85 , CI: $1.01-3.42 \mathrm{p}<.05)$, and been blackmailed as a result of selling sex $(37.1 \%$ vs. $19.9 \%$ aOR: 2.33 , CI: $1.22-4.47 \mathrm{p}<.05$ ) [Table 2].

In analyses examining the association between health outcomes and forced sex by a client, women reporting forced sex were significantly more likely to suffer from symptoms of depression ( $73.9 \%$ vs. $58.8 \%$, OR: $1.98 \mathrm{CI}$ : $1.06-3.68 \mathrm{p}<.05$, aOR: $2.15 \mathrm{CI}: 1.10-4.16 \mathrm{p}<.05)$, to report "no", "difficult" or "somewhat difficult" access to condoms (68.6\% vs. $42.0 \%$ OR: $3.01 \mathrm{CI}: 1.67-5.43$ $\mathrm{p}<.001$, aOR: 3.32 CI: $1.75-6.26 \mathrm{p}<.001)$, and report an unwanted pregnancy $(29.2 \%$ vs. $22.6 \%$, OR: $1.42 \mathrm{CI}$ : $.74-2.72 \mathrm{p}=.29$, aOR: 2.69 CI: $1.12-6.49 \mathrm{p}<.05$ ) after adjusted analysis. Participants who reported forced sex from a client were also significantly less likely to have an STI test in the past 12 months $(32.9 \%$ vs. $49.7 \%$ OR: .49 CI: $.26-.91 \mathrm{p}<.05$, aOR: .49 CI: $.26-.91 \mathrm{p}<.05)$ [Table 2].

\section{Discussion}

These findings demonstrate extensive client-perpetrated sexual violence against FSW in The Gambia, with over one in four women (29\%) reporting having been forced to have sex with a client in their lifetime. This analysis adds to a growing body of research demonstrating the negative health impacts of sexual violence against FSW. Women who had been forced to have sex by a client were significantly more likely to be victims of other 
Table 1 Baseline demographics by group

\begin{tabular}{|c|c|c|c|c|}
\hline & Total sample $n=251$ & Exposed to forced sex $n=70$ & Unexposed to forced sex $n=171$ & p-value \\
\hline Forced sex: n (\%) & $70(29.0)$ & - & - & - \\
\hline HIV positive: $\mathrm{n}(\%)$ & $40(16.8)$ & $13(18.6)$ & $26(15.2)$ & $.52^{+}$ \\
\hline Age distribution: Median & 30.0 & 30.5 & 30.0 & $.54 \wedge$ \\
\hline Inter Quartile Range & $26-35$ & $26-36$ & $26-35$ & \\
\hline Median number of children & 1.0 & 2.0 & 1.0 & $.19 \wedge$ \\
\hline Inter Quartile Range & $1-3$ & $1-3$ & $1-3$ & \\
\hline Median age at entry into sex work in years & 25.0 & 24.0 & 25.0 & $.43 \wedge$ \\
\hline Inter Quartile Range & $20-30$ & $19-28$ & $20-30$ & \\
\hline Median years in sex work & 4.0 & 4.5 & 4.0 & $.09 \wedge$ \\
\hline Inter Quartile Range & $2-9$ & $2-10$ & $2-8$ & \\
\hline Marriage status: n (\%) & & & & $.27^{+}$ \\
\hline Married/Cohabitating & $5(2.0)$ & $2(2.9)$ & $3(1.8)$ & \\
\hline Widowed/Divorced & $173(68.9)$ & $54(77.2)$ & $112(65.5)$ & \\
\hline Single/never married & $57(22.7)$ & $13(18.6)$ & $43(25.1)$ & \\
\hline Education level: $\mathrm{n}(\%)$ & & & & $.86^{+}$ \\
\hline Never attended & $74(30.0)$ & $20(29.0)$ & $53(31.2)$ & \\
\hline Some or completion of primary school & $75(30.4)$ & $23(33.3)$ & $48(28.2)$ & \\
\hline Some or completion of secondary school & $92(37.3)$ & $25(36.2)$ & $65(38.2)$ & \\
\hline Post high school, vocational or college & $6(2.4)$ & $1(1.5)$ & $5(2.4)$ & \\
\hline Region of origin: $\mathrm{n}(\%)$ & & & & $.41^{+}$ \\
\hline Kanifing municipality & $30(12.1)$ & $12(17.1)$ & $16(9.4)$ & \\
\hline Banjul & $10(4.0)$ & $5(7.1)$ & $5(2.9)$ & \\
\hline West Coast region & $24(9.7)$ & $5(7.1)$ & $17(10.0)$ & \\
\hline North bank region & $18(7.3)$ & $6(8.6)$ & $12(7.1)$ & \\
\hline Lower River region & $6(2.4)$ & $1(1.4)$ & $5(2.9)$ & \\
\hline Upper River region & $16(6.5)$ & $3(4.3)$ & $13(7.7)$ & \\
\hline Outside Gambia & $143(57.7)$ & $38(54.3)$ & $101(59.4)$ & \\
\hline
\end{tabular}

$+p$-value calculated from Pearson chi squared test.

$\wedge p$-value calculated from Wilcoxon rank-sum test.

violent crimes such as being beaten up or tortured, which may further increase their vulnerability for negative health outcomes.

Victimization was significantly associated with unwanted pregnancy. Sexual violence can impart risk for unintended pregnancy directly, as well as put survivors on a trajectory of limited control over condom negotiation and use in future sexual encounters [20,26]. The significant association between sexual violence and unwanted pregnancies among FSW in The Gambia is potentially contextualized by previous research among FSW, which showed that condoms are often not used during incidents of forced sex [12,22,23], and is consistent with previous research showing that victims of forced sex report high percentages of unwanted pregnancy and abortion $[35,59,60]$. Together, these findings call for a more integrated response to sexual violence in The Gambia for survivors of forced sex, including access to emergency contraceptives (EC).

Ongoing initiatives in The Gambia to address sexual violence include a national action plan and development of a communication strategy on gender-based violence. The Gambia recently reaffirmed its commitment to confronting sexual violence by approving the Sexual Offences Bill of 2013, which seeks to punish offenders for sexual violence, harassment, and other threatening behavior [61]. However, the practical implementation of the bill has not been studied and there continues to be limited guidelines for service provision for survivors of sexual violence. The evidence suggests that providing services to survivors of violence, including access to EC, could prevent unwanted pregnancies and abortions, both of which may have negative health consequences for Gambian women, especially in contexts 
Table 2 Associations of forced sex by a client (FS) with other forms of violence and health outcomes

\begin{tabular}{|c|c|c|c|c|c|c|c|}
\hline & $\begin{array}{l}\text { Total sample: } \\
\mathrm{n}(\%) \mathrm{n}=\mathbf{2 5 1}\end{array}$ & $\begin{array}{l}\text { Exposed to FS: } \\
\mathrm{n}(\%) \mathrm{n}=70\end{array}$ & $\begin{array}{l}\text { Unexposed to FS: } \\
\mathrm{n}(\%) \mathrm{n}=171\end{array}$ & $\begin{array}{l}\text { Crude OR } \\
(95 \% \mathrm{Cl})\end{array}$ & P-value & $\begin{array}{l}\text { Adjusted OR^ } \\
(95 \% \mathrm{Cl})\end{array}$ & P-value \\
\hline \multicolumn{8}{|l|}{ Violence Outcomes: } \\
\hline $\begin{array}{l}\text { Ever beaten up as a result of selling } \\
\text { sex }\end{array}$ & $49(21.1)$ & $22(31.9)$ & $27(16.6)$ & $2.36(1.22-4.53)$ & $.01^{*}$ & $2.44(1.22-4.85)$ & $.01^{*}$ \\
\hline By regular client & $13(26.5)$ & & & & & & \\
\hline By one-time client & $10(20.4)$ & & & & & & \\
\hline By non- paying partner & $10(20.4)$ & & & & & & \\
\hline By uniformed officer & $9(18.4)$ & & & & & & \\
\hline By family member & $6(12.2)$ & & & & & & \\
\hline $\begin{array}{l}\text { Ever verbally or physically harassed } \\
\text { as a result of selling sex }\end{array}$ & $96(38.5)$ & $31(44.3)$ & $64(37.4)$ & $1.33(.76-2.34)$ & .32 & $1.25(.70-2.26)$ & .45 \\
\hline Ever tortured as a result of selling sex & $81(32.7)$ & $31(44.3)$ & $49(28.8)$ & $1.96(1.10-3.49)$ & $.02^{*}$ & $1.85(.99-3.42)$ & $.05^{*}$ \\
\hline $\begin{array}{l}\text { Ever blackmailed as a result of selling } \\
\text { sex }\end{array}$ & $60(24.5)$ & $26(37.1)$ & $34(19.9)$ & $2.38(1.30-4.40)$ & $<.01^{*}$ & $2.33(1.22-4.47)$ & $.01^{*}$ \\
\hline $\begin{array}{l}\text { Ever offered more money to have sex } \\
\text { without a condom }\end{array}$ & $102(42.1)$ & $30(42.9)$ & $72(42.9)$ & $1.00(.57-1.76)$ & 1.0 & $.96(.53-1.73)$ & .89 \\
\hline Ever jailed & $11(4.8)$ & $6(9.5)$ & $5(3.1)$ & $3.24(.95-11.04)$ & .06 & $2.29(.62-8.50)$ & .21 \\
\hline \multicolumn{8}{|l|}{ Health Outcomes: } \\
\hline Depressive Symptoms & $154(62.6)$ & $51(73.9)$ & $100(58.8)$ & $1.98(1.06-3.68)$ & $.03^{*}$ & $2.15^{\wedge}(1.10-4.16)$ & $.02^{*}$ \\
\hline STI test in the past 12 months & $112(45.3)$ & $23(32.9)$ & $84(49.7)$ & $.49(.28-.89)$ & $.02^{*}$ & $.49 \wedge(.26-.91)$ & $.02^{*}$ \\
\hline Unwanted pregnancy (Over lifetime) & $54(23.8)$ & $19(29.2)$ & $35(22.6)$ & $1.42(.74-2.72)$ & .29 & $2.69>(1.12-6.49)$ & $.03^{*}$ \\
\hline Difficult or no access to condoms ${ }^{+}$ & $121(48.9)$ & $48(68.6)$ & $71(42.0)$ & $3.01(1.67-5.43)$ & $<.001^{*}$ & $3.32 \wedge(1.75-6.26)$ & $<.001^{*}$ \\
\hline
\end{tabular}

*p-value significant at .05 level.

Screen for depressive symptoms through the question "Have you felt sad or had a depressed mood for more than two weeks at a time in the last three years". "Variable coded dichotomously comparing "no", "difficult", or "somewhat difficult" access compared to "very easy" or "somewhat easy" access to condoms.

$\wedge$ Adjusted for age, age of entry into sex work, years spent in sex work, and HIV status.

>Adjusted for age, age of entry into sex work, years spent in sex work, HIV status, and number of childre006E.

where abortion is illegal and women may be seeking abortion services in unsafe environments [44].

Findings from this study show high levels of depressive symptoms among FSW in The Gambia (62.6\%). Previous research, using a modified Edinburgh Depression Scale, has shown that approximately $10.3 \%$ of women of reproductive age in the general population in The Gambia reported depressive symptoms that suggest a substantial probability of depression [62]. While these findings are not directly comparable to the current study, given the use of a different screening question for depressive symptoms, this suggests that the prevalence of depressive symptoms may be elevated among FSW compared to women in the general population. Current findings highlight FSW's vulnerability for poor mental health outcomes and the need for the availability of mental health services for this population. In addition, forced sex is associated with depressive symptoms, which calls attention to the role that sexual violence may play in mental health outcomes for FSW. These findings advance earlier evidence that violence affects the mental health of women in general $[63,64]$ as well as FSW, who are estimated to be two to five times more likely to report depression if they have experienced forced sex compared to women who did not report forced sex $[25,42]$. The observed prevalence of depressive symptoms strengthens the call of past research for mental health services for survivors of violence. In Nepal, researchers found that depression among FSW was also associated with HIV risk behavior, emphasizing the need to address mental health issues among FSW as part of a comprehensive HIV prevention package [42].

In The Gambia there is limited research on mental health issues and limited infrastructure for mental health treatment, including lack of human resources and budget allocations for services [65]. The Gambia's Ministry of Health and Social Welfare collaborated with the WHO and finalized a strategic plan to improve the treatment gap in mental health services in 2006 [66]. The major objectives of this plan were to provide accessible mental health and substance abuse services, and protect the rights of people with mental and substance use disorders. This plan could be strengthened by including a focus on addressing the mental health needs of FSW and survivors of sexual violence at the community level. This could include supporting the efforts of local 
organizations to build the capacity of clinical and nonclinical staff to respond to survivors' needs, engage in community sensitization efforts surrounding mental health disorders, FSW, and violence, as well as increase resource allocation for improved service delivery. Research in The Gambia, from 2011, has suggested that providing medication for depression and other mental health disorders may not be a feasible immediate strategy to treat depression, given the current cost-barriers and absence of prescribers, which greatly limits widespread use [67]. Intermediate strategies to support FSW and survivors of violence in The Gambia could include psychotherapeutic support groups, which has shown some promise as a depression intervention among HIV positive adults in Uganda [68], sociotherapy to build social bonds, and group interpersonal therapy which have both shown positive results in responding to the mental health needs of survivors of violence in Rwanda [69] and rural Uganda [70]. FSW-specific research must be conducted to learn if these interventions show promise for FSW populations.

Current evidence suggests that sexual violence victimization at the hands of clients is also associated with lower access to condoms and decreased likelihood of receiving an STI test in the past 12 months. These findings point to an unmet need in sexual health services among FSW who are survivors of violence. Qualitative research has suggested that in situations where FSW have immediate emergencies that threaten their safety, such as violence and abuse, they are less likely to focus on relatively longer-term issues of HIV, STIs, and pregnancy [71]. This may explain why women who report having experienced forced sex also report having less access to condoms and are less likely to be tested for STIs; in other words, crisis situations may undermine their ability to plan and control their sexual health. Responding to the unmet need for sexual health services through outreach to FSW could be a potential strategy to reach the women who have less access to services, including survivors of violence. Reaching these women, who are most vulnerable for poor health outcomes, is an important strategy to improve health and wellbeing for Gambian FSW.

\section{Limitations}

A limitation of this cross-sectional design is that the direction of the associations cannot be determined, and while forced sex is associated with various health outcomes, causality cannot be shown. The sample for this study was relatively small and recorded a small number of events, which resulted in large confidence intervals. The sample was also derived from chain-referral and venue-based convenience sampling due to the difficulty with recruitment among this extremely mobile and vulnerable population in The Gambia. Due to nonrandomized nature of this recruitment method, it cannot be determined if this sample is fully representative of FSW in The Gambia. Furthermore, data on what individuals were recruited by whom or from where were not recorded, so that data analysis adjusted for clustering by recruitment chain or venue was not possible. Future studies could address these difficulties by employing Respondent Driven Sampling (RDS) as a recruitment method. RDS was not used in the present study due to time and budget restrictions.

The current analysis, which examines forced sex perpetrated by clients, does not include forced sex by other perpetrators. The measure may therefore underestimate the prevalence of forced sex overall among FSW because it does not reflect victimization from non-paying partners, family members, police, strangers and others. However, client violence is the predominant type of sexual violence reported by FSW in many global settings $[13,23,31]$, and is an important exposure to study in its own right, as it may have different associations with health outcomes than sexual violence at the hands of other perpetrators [72]. A surprising result was that one third of participants recorded having been "tortured as a result of selling sex". Future research is needed to determine what abuses women are referring to when participants report having been tortured in this context. In addition, this questionnaire was intended to measure depressive symptoms and cannot be used to quantify the prevalence of clinical depression among FSW. Sexual violence indicators were reported in face-to-face interviews where participants may have been uncomfortable disclosing victimization. However, the anonymous nature of the interview, training of female interviewers to be sensitive, and participant's ability to refuse to answer any question may have helped to mitigate under-reporting.

\section{Conclusions}

These data provide valuable insights into the prevalence of, and health outcomes associated with, clientperpetrated sexual violence among FSW in The Gambia. More research is needed in The Gambia to examine the prevalence and correlates of forced sex against FSW by non-clients as well as sexual violence in the general population. Current findings point to an unmet need for health services for FSW survivors of sexual violence. Responding to the physical and mental health needs of survivors in The Gambia, including outreach to FSW, is a priority to improve FSW and survivor health more generally. A response to sexual violence victimization that includes the availability of emergency contraceptives, post-exposure prophylaxis, and mental health crisis services, could better meet the post-assault health 
needs of Gambian FSW as well as women in the general population.

Efforts to reduce sexual violence against sex workers should be prioritized in The Gambia as a way to improve the health and safety of FSW as well as address the spread of HIV/STIs. HIV/STI prevention programs often employ individual-level behavior interventions that address individual acquisition and transmission of sexually transmitted infections. However, in the cases of forced sex where women may be unable to practice preventive behaviors, interventions that target individuallevel HIV risk factors such as condom use can be less potent. Programs and policies that address violence and the larger contextual issues that contribute to unsafe sex and inconsistent condom use may be more effective [73]. Recent work that modeled HIV incidence rates based on data from Kenya estimated that if violence against FSW could be reduced to $2.4 \%$, compared to the current prevalence of $32 \%$, that new HIV infections could be decreased by $27 \%$ among FSW, and $12 \%$ among the general adult population [74]. This work quantifies the potential impact that violence reduction among FSW can have on national HIV infection rates in an African context. The high rate of sexual violence among FSW is not only an issue of human rights and safety but also an issue of sexual, reproductive, and mental health. The Gambia's National Reproductive Health Policy Plan (2007-2014) emphasizes the need to reduce sexual violence and ensure proper support for victims to improve reproductive health outcomes of women, but FSW are not mentioned specifically in these objectives [75]. Given the unique needs of FSW and their exposure to additional forms of violence, specifically client violence, suggests that including strategies to reduce sexual violence against FSW in The Gambia's strategic plan would be an important step in improving sexual, physical, and mental health outcomes for Gambian sex workers and the population more broadly.

\section{Competing interests}

The authors declare that they have no competing interests.

\section{Authors' contributions}

DD, NC, FD and SB conceived and designed the study. NC, SB, and SP provided technical support to the implementation to the study. JS analyzed the data with support from MD and AG. JS coordinated the writing of the manuscript with substantive contributions and critical revisions from $A G, M D$, SP, EP and SB. All authors read and approved the final manuscript.

\footnotetext{
Acknowledgements

This study was a result of the commitment, dedication, and courage of many key people and partners. We therefore wish to first and foremost thank the female sex workers who participated in this study with little personal benefit. We would like to thank the field workers, data collectors, and their supervisors for all the hard work and determination for the successful completion of the study. We also want to thank the National AIDS Secretariat, Action Aid International, UNAIDS, Network of AIDS Service Organizations - The Gambia, Jobot Laboratories, The Global Fund, Enda Santé, and Johns Hopkins School of Public Health for their financial and
}

technical support to conduct this study. We would also like to thank Krystal Mason, who provided technical support to the implementation of the study, and Jaegan Loum who coordinated recruitment, survey administration, and biological specimen collection.

\section{Author details}

1Johns Hopkins School of Public Health, 615 N Wolfe St. \#5041, Baltimore, MD 21205, USA. Enda Santé Senegal, 56, Comico VDN, BP 3370 Dakar, Sénégal. ${ }^{3}$ University of Gaston Berger, P.O. Box 17470, St Louis, Sénégal. ${ }^{4}$ Lilunga House, Fifth Floor, Somhlolo Street, Mbabane, Swaziland.

Received: 2 April 2014 Accepted: 25 February 2015

Published online: 19 March 2015

\section{References}

1. Ahoyo AB, Alary M, Méda H, Ndour M, Batona G, Bitéra R, et al. Enquête de surveillance intégrée du VIH et des autres infections sexuellement transmissibles chez les travailleuses du sexe au Bénin en 2002. Cahiers d'études et de recherches francophones/Santé. 2007;17(3):143-51.

2. Diallo B, Alary M, Barry A, Rashed S. HIV epidemic among female sex workers in Guinea: prevalence, associated risk factors, vulnerability and trend from 2001 to 2007]. Rev Epidemiol Sante Publique. 2010;58(4):245.

3. Godin G, Tinka Bah A, Sow A, Minani I, Morin D, Alary M. Correlates of condom use among sex workers and their boyfriends in three West African countries. AIDS Behav. 2008;12(3):441-51.

4. Kane CT, Diawara S, Ndiaye HD, Diallo PA, Wade AS, Diallo AG, et al Concentrated and linked epidemics of both HSV-2 and HIV-1/HIV-2 infections in Senegal: public health impacts of the spread of HIV. Int J STD AIDS. 2009;20(11):793-6.

5. Lajoie J, Massinga Loembe M, Poudrier J, Guedou F, Pepin J, Labbe AC, et al. Blood soluble human leukocyte antigen $\mathrm{G}$ levels are associated with human immunodeficiency virus type 1 infection in Beninese commercial sex workers. Hum Immunol. 2010;71(2):182-5.

6. Wang C, Hawes SE, Gaye A, Sow PS, Ndoye I, Manhart LE, et al. HIV prevalence, previous HIV testing, and condom use with clients and regular partners among Senegalese commercial sex workers. Sex Transm Infect. 2007;83(7):534-40

7. Peitzmeier S, Mason K, Ceesay N, Diouf D, Drame F, Loum J, et al. A crosssectional evaluation of the prevalence and associations of HIV among female sex workers in the Gambia. Int J STD AIDS. 2013;25(4):244-52.

8. Hawkes S, West B, Wilson S, Whittle H, Mabey D. Asymptomatic carriage of Haemophilus ducreyi confirmed by the polymerase chain reaction. Genitourin Med. 1995;71(4):224-7.

9. Pepin J, Dunn D, Gaye I, Alonso P, Egboga A, Tedder R, et al. HIV-2 infection among prostitutes working in The Gambia: association with serological evidence of genital ulcer diseases and with generalized lymphadenopathy. AIDS. 1991;5(1):69-75.

10. Wingood GM, DiClemente RJ. The effects of an abusive primary partner on the condom use and sexual negotiation practices of African-American women. Am J Public Health. 1997:87(6):1016-8.

11. Deering KN, Bhattacharjee P, Mohan H, Bradley J, Shannon K, Boily M-C, et al. Violence and HIV risk among female sex workers in southern India. Sex Transm Dis. 2013;40(2):168-74.

12. Choi SY, Holroyd E. The influence of power, poverty and agency in the negotiation of condom use for female sex workers in mainland China. Cult Health Sex. 2007;9(5):489-503.

13. Decker MR, Wirtz AL, Moguilnyi V, Peryshkina A, Ostrovskaya M, Nikita M, et al. Female sex workers in three cities in Russia: HIV prevalence, risk factors and experience with targeted HIV prevention. AIDS Behav. 2014;18(6):562-72.

14. Amaro H. Love, sex, and power: considering women's realities in HIV prevention. Am Psychol. 1995;50(6):437.

15. Swain SN, Saggurti N, Battala M, Verma RK, Jain AK. Experience of violence and adverse reproductive health outcomes, HIV risks among mobile female sex workers in India. BMC Public Health. 2011;11(1):357.

16. Directorate General of Health Services. National AIDS/STD Program. Report on the Second National Expanded HIV Surveillance, 1999-2000 Bangladesh. Dhaka: AIDS and STD Control Programme, Ministry of Health and Family Welfare, Government of Bangladesh; 2000. p. 47.

17. Hubbard D, Zimba E, Pong P, Longo P, Ditmore M, Surtees R, et al. Sex work and the law in Namibia: a culture-sensitive approach. Res Sex Work. 2003;18 (6):10-1. 
18. Chersich MF, Luchters SM, Malonza IM, Mwarogo P, King'ola N, Temmerman M. Heavy episodic drinking among Kenyan female sex workers is associated with unsafe sex, sexual violence and sexually transmitted infections. Int J STD AIDS. 2007;18(11):764-9.

19. Braunstein SL, Ingabire CM, Geubbels E, Vyankandondera J, Umulisa MM, Gahiro E, et al. High burden of prevalent and recently acquired HIV among female sex workers and female HIV voluntary testing center clients in Kigali, Rwanda. PLoS One. 2011:6(9):e24321.

20. WHO. Violence Against Women and HIV/AIDS: Critical Intersections. Violence Against sex Workers and HIV Prevention. 2005.

21. UNAIDS. Report on the Global HIV/AIDS Epidemic 2008. Geneva: UNAIDS; 2008.

22. Mooney A, Kidanu A, Bradley HM, Kumoji EK, Kennedy CE, Kerrigan D. Workrelated violence and inconsistent condom use with non-paying partners among female sex workers in Adama City, Ethiopia. BMC Public Health. 2013;13(1):1-10.

23. Beattie TS, Bhattacharjee P, Ramesh BM, Gurnani V, Anthony J, Isac S, et al. Violence against female sex workers in Karnataka state, south India: impact on health, and reductions in violence following an intervention program. BMC Public Health. 2010;10:476.

24. Decker MR, McCauley HL, Phuengsamran D, Janyam S, Seage 3rd GR, Silverman JG. Violence victimisation, sexual risk and sexually transmitted infection symptoms among female sex workers in Thailand. Sex Transm Infect. 2010;86(3):236-40.

25. Ulibarri MD, Hiller SP, Lozada R, Rangel MG, Stockman JK, Silverman JG, et al. Prevalence and characteristics of abuse experiences and depression symptoms among injection drug-using female sex workers in Mexico. J Environ Public Health. 2013;2013:631479.

26. Dunkle KL, Decker MR. Gender-based violence and HIV: reviewing the evidence for links and causal pathways in the general population and highrisk groups. Am J Reprod Immunol (New York, NY : 1989). 2013;69 Suppl 1:20-6.

27. Decker MR, Seage III GR, Hemenway D, Raj A, Saggurti N, Balaiah D, et al. Intimate partner violence functions as both a risk marker and risk factor for women's HIV infection: findings from Indian husband-wife dyads. J Acquir Immune Defic Syndr(1999). 2009;51(5):593.

28. Dunkle KL, Jewkes RK, Nduna M, Levin J, Jama N, Khuzwayo N, et al. Perpetration of partner violence and HIV risk behaviour among young men in the rural Eastern Cape. South Africa Aids. 2006;20(16):2107-14.

29. Jewkes R, Dunkle K, Koss MP, Levin JB, Nduna M, Jama N, et al. Rape perpetration by young, rural South African men: prevalence, patterns and risk factors. Soc Sci Med. 2006:63(11):2949-61.

30. Caceres CF, Aggleton P, Galea JT. Sexual diversity, social inclusion and HIV/ AIDS. AIDS (London, England). 2008;22 Suppl 2:S45-55.

31. Decker MR, Wirtz AL, Baral SD, Peryshkina A, Mogilnyi V, Weber RA, et al. Injection drug use, sexual risk, violence and STI/HIV among Moscow female sex workers. Sex Transm Infect. 2012;88(4):278-83.

32. Khan MR, Turner AN, Pettifor A, Van Damme K, Rabenja NL, Ravelomanana $\mathrm{N}$, et al. Unmet need for contraception among sex workers in Madagascar. Contraception. 2009;79(3):221-7.

33. Sutherland EG, Alaii J, Tsui S, Luchters S, Okal J, King'ola N, et al. Contraceptive needs of female sex workers in Kenya-a cross-sectional study. Eur J Contracept Reprod Health Care. 2011;16(3):173-82.

34. Shah I, Ahman E. Unsafe abortion: global and regional incidence, trends, consequences, and challenges. J Obstet Gynaecol Can. 2009;31(12):1149-58.

35. Kalonda J. [Sexual violence in Congo-Kinshasa: necessity of decriminalizing abortion]. Rev Med Brux. 2011;33(5):482-6.

36. Kalyanwala S, Zavier AJ, Jejeebhoy S, Kumar R. Abortion experiences of unmarried young women in India: evidence from a facility-based study in Bihar and Jharkhand. Int Perspect Sex Reprod Health. 2010;36(2):62-71.

37. Gessessew A. Unwanted pregnancy and it's impact on maternal health and utilization of health services in Tigray Region (Adigrat Hospital). Ethiop Med J. 2009;47(1):1-8

38. Duran B, Oetzel J, Parker T, Malcoe LH, Lucero J, Jiang Y. Intimate partner violence and alcohol, drug, and mental disorders among American Indian women from southwest tribes in primary care. American Indian \& Alaska Native Mental Health Research. J Natl Cent. 2009;16(2):11-27.

39. Edwards VJ, Black MC, Dhingra S, McKnight-Eily L, Perry GS. Physical and sexual intimate partner violence and reported serious psychological distress in the 2007 BRFSS. Int J Public Health. 2009;54(1):37-42.
40. Hurwitz EJH, Gupta J, Liu R, Silverman JG, Raj A. Intimate partner violence associated with poor health outcomes in US South Asian women. J Immigr Minor Health. 2006;8(3):251-61

41. Ellsberg $M$, Jansen HA, Heise L, Watts $\mathrm{CH}$, Garcia-Moreno C. Intimate partner violence and women's physical and mental health in the WHO multicountry study on women's health and domestic violence: an observational study. Lancet. 2008;371(9619):1165-72.

42. Sagtani RA, Bhattarai S, Adhikari BR, Baral D, Yadav DK, Pokharel PK. Violence, HIV risk behaviour and depression among female sex workers of eastern Nepal. BMJ Open. 2013;3(6):e002763. doi:10.1136/bmjopen-2013- 002763.

43. U.S Department of State. Country Reports on Human Rights Practices. The Gambia: Bureau of Democracy Human Rights and Labor; 2000.

44. UNESCO. Family Planning Profiles. The Gambia: Population Division of the Department for Economic and Social Affairs of the United Nations, Population Policy Database; 2013.

45. WHO. Putting Women First: Ethical and Safety Recommendations for Research on Domestic Violence Against Women. Geneva, Switzerland: WHO; 2001.

46. Jewkes R, Sen P, Garcia-Moreno C. Sexual Violence. 2002.

47. NRC. Estimating the Incidence of Rape and Sexual Assault in. Washington DC: The National Academic Press; 2013.

48. Loza O, Strathdee SA, Lozada R, Staines H, Ojeda VD, Martínez GA, et al. Correlates of early versus later initiation into sex work in two Mexico-US border cities. J Adolesc Health. 2010;46(1):37-44.

49. Roe-Sepowitz DE. Juvenile entry into prostitution the role of emotional abuse. Violence Against Women. 2012;18(5):562-79.

50. Kramer LA, Berg EC. A survival analysis of timing of entry into prostitution: the differential impact of race, educational level, and childhood/adolescent risk factors. Sociol Inq. 2003;73(4):511-28.

51. Kelly JA, Murphy DA, Bahr GR, Koob JJ, Morgan MG, Kalichman SC, et al. Factors associated with severity of depression and high-risk sexual behavior among persons diagnosed with human immunodeficiency virus (HIV) infection. Health Psychol. 1993;12(3):215.

52. Morrison MF, Petitto JM, Ten Have T, Gettes DR, Chiappini MS, Weber AL, et al. Depressive and anxiety disorders in women with HIV infection. Am J Psychiatr. 2002;159(5):789-96.

53. Karamagi CA, Tumwine JK, Tylleskar T, Heggenhougen K. Intimate partner violence against women in eastern Uganda: implications for HIV prevention. BMC Public Health. 2006;6(1):1-12.

54. Maman S, Mbwambo JK, Hogan NM, Kilonzo GP, Campbell JC, Weiss E, et al HIV-positive women report more lifetime partner violence: findings from a voluntary counseling and testing clinic in Dar es Salaam, Tanzania. Am J Public Health. 2002:92(8):1331-7.

55. Gielen AC, McDonnell KA, Burke JG, O'Campo P. Women's lives after an HIV-positive diagnosis: disclosure and violence. Matern Child Health J. 2000:4(2):111-20.

56. Chen JL, Phillips KA, Kanouse DE, Collins RL, Miu A. Fertility desires and intentions of HIV-positive men and women. Fam Plan Perspect. 2001;33 (4):144-65.

57. Nattabi B, Li J, Thompson SC, Orach CG, Earnest J. A systematic review of factors influencing fertility desires and intentions among people living with HIV/AIDS: implications for policy and service delivery. AIDS Behav. 2009;13 (5):949-68.

58. StataCorp. Stata Statistical Software: Release 12. In., vol. 12. StataCorp: College Station, TX; 2011.

59. Misganaw AC, Worku YA. Assessment of sexual violence among street females in Bahir-Dar town, North West Ethiopia: a mixed method study. BMC Public Health. 2013;13:825

60. Molla M, Ismail S, Kumie A, Kebede F. Sexual violence among female street adolescents in Addis Ababa, April 2000. Ethiop J Health Dev. 2002;16(2):119-28.

61. UNDP. Crucial Act passed to address 'increased' sexual offences. In. Edited by Gambia Ui; 2013.

62. Coleman R, Morison L, Paine K, Powell RA, Walraven G. Women's reproductive health and depression. Soc Psychiatry Psychiatr Epidemiol. 2006;41(9):720-7.

63. Golding JM. Intimate partner violence as a risk factor for mental disorders: a meta-analysis. J Fam Violence. 1999;14(2):99-132.

64. Rees S, Silove D, Chey T, Ivancic L, Steel Z, Creamer M, et al. Lifetime prevalence of gender-based violence in women and the relationship with mental disorders and psychosocial function. Jama. 2011;306(5):513-21. 
65. Saraceno B, van Ommeren M, Batniji R, Cohen A, Gureje O, Mahoney J, et al. Barriers to improvement of mental health services in low-income and middle-income countries. Lancet. 2007;370(9593):1164-74.

66. WHO, Abuse DoMHS. The Gambia Country Summary. In: Effective and Humane Mental Healt Treatment and Care for all. Geneva: WHO; 2007.

67. Thome J, Marenah E, Moraru D, Höppner J, Nyan O. Availability of psychiatric medication in an urban area of The Gambia/West Africa. World J Biol Psychiatry. 2011;12(S1):114-7.

68. Nakimuli-Mpungu E, Wamala K, Okello J, Alderman S, Odokonyero R, Musisi S, et al. Outcomes, feasibility and acceptability of a group support psychotherapeutic intervention for depressed HIV affected Ugandan adults: A pilot study. J Affect Disord. 2014;166:144-50.

69. Scholte WF, Verduin F, Kamperman AM, Rutayisire T, Zwinderman AH, Stronks K. The effect on mental health of a large scale psychosocial intervention for survivors of mass violence: a quasi-experimental study in Rwanda. PLoS One. 2011;6(8):e21819.

70. Bolton P, Bass J, Neugebauer R, Verdeli H, Clougherty KF, Wickramaratne P, et al. Group interpersonal psychotherapy for depression in rural Uganda: a randomized controlled trial. Jama. 2003;289(23):3117-24.

71. Okal J, Chersich MF, Tsui S, Sutherland E, Temmerman M, Luchters S. Sexual and physical violence against female sex workers in Kenya: a qualitative enquiry. AIDS Care. 2011;23(5):612-8.

72. Decker MR, Pearson E, Illangasekare SL, Clark E, Sherman SG. Violence against women in sex work and HIV risk implications differ qualitatively by perpetrator. BMC Public Health. 2013;13(1):876.

73. Shannon K, Kerr T, Allinott S, Chettiar J, Shoveller J, Tyndall MW. Social and structural violence and power relations in mitigating HIV risk of drug-using women in survival sex work. Soc Sci Med. 2008:66(4):911-21.

74. Decker MR, Wirtz AL, Pretorius C, Sherman SG, Sweat MD, Baral SD, et al. Estimating the impact of reducing violence against female sex workers on HIV epidemics in Kenya and Ukraine: a policy modeling exercise. Am J Reprod Immunol. 2013;69(s1):122-32.

75. Department for the State of Health and Social Welfare. Republic of The Gambia National Reproductive Health Policy (2007-2014). In. Edited by Jallow M; 2007.

\section{Submit your next manuscript to BioMed Central and take full advantage of:}

- Convenient online submission

- Thorough peer review

- No space constraints or color figure charges

- Immediate publication on acceptance

- Inclusion in PubMed, CAS, Scopus and Google Scholar

- Research which is freely available for redistribution 